put the services of the best naturalists at the disposal of students, and offer free tuition and living to come and study with them. Libraries, great museums, great teachers are made available to him who would work and had the requisite capacity.

All these advantages will, however, count for nothing if zoological research do not attract the best men and if the best men be not accorded time and means for research. Our best students slip from our grasp to go into other professions or into commerce, because we can offer them no outlook but teaching administration, and a salary regulated by the law of supply and demand. We must urge without ceasing upon college trustees and corporations the necessity of freedom for research and liberal salaries if America is to contribute her share to the advance of zoology in the tiventieth century.

\section{THE CARNEGIE TECHNICAL SCHOOL AT} PITTSBURG.

TWO of the addresses delivered by presidents of sections of the American Association for the Advancement of Science at the recent Denver meeting were concerned with scientific and technical education. Mr. J. A. Brashear, Chancellor of the Western University of Pennsylvania, described the plans, drawn up at Mr. A. Carnegie's request, for a great technical college at Pittsburg, and Prof. C. M. Woodward, Dean of the School of Engineering and Architecture, Washington University, St. Louis, took as his text the differences between the educational ideals of to-day and of the time when education was considered merely as needful to the "embellishments of life." The movement towards a study of the materials and forces of Nature and the problem of modern life-sociological, commercial and industrial-has produced a change of front as remarkable as it is gratifying. Out of the vast extension of the horizon of human activities which the movement has promoted, and a corresponding multiplication of occupations, has come an imperative demand for better education and for technically educated men. The scheme for the Carnegie Technical School has been drawn up with the intention of suggesting how to train students to supply this want.

Reference has already been made (July 25, p. 319 ) to the report of the committee appointed to determine the best plan and most suitable scope of the new institution which $\mathrm{Mr}$. Carnegie is prepared to build, equip and endow in the city of Pittsburg. Further details are given hy Mr. Brashear in his address, and are here summarised. After a careful discussion of the plan of procedure, the committee on the plan and scope of the proposed school decided to call to their assistance, as an advisory board, Dr. Robert H. Thurston, Prof. J. B. Johnson, Dr. Thomas Gray and Dr. Victor Alderson, acting president of the Armour Institute of Chicago.

Each member of the advisory board formulated his plans without consultation with other members of the committee, yet it is a matter of interest to know that the expressed views of the advisory board as individual members were so nearly in accord on the general principles formulated for the great school of technology. The following is an outline of the scheme for the new technical school :-

First, as to site. The advisory board suggested that not less than fifty acres be secured, and as a tract of sixty-five acres is available not far distant from the Carnegie Institute, the board strongly recommended its purchase, or a similar piece of land as near by as it is possible to obtain it. A potent reason for placing the technical school near the Carnegie Institute is the fact that its library is rich in technical and other valuable works which need not be duplicated in the technical school library; indeed the association of the school with the great and increasingly valuable library, museum, art gallery and Academy of Science and Art is certainly to be desired.

As to the buildings for the technical school, but little has been suggested. Dr. Thurston in his report has given an interesting ressume of the space occupied by the student in the various German technical schools, remarking that the German motto " viel Platz, viel Licht, viel Luft," would be an excellent guide. in determining this question. $\mathrm{He}$ says: "Ample space, good light and plenty of fresh air are essential, although the architect, who should be the most earnest and intelligent of them all, is often woefully deficient in appreciation of their importance when brain work is going on." Dr. Thurston further states that taking figures from the best German technical schools, which are based on the largest experience, the school of architecture at Berlin has 150 feet floor space per student, the engineering school 35 feet; but this latter department is so much overcrowded that arrangements are being made to give the student in this department at least 75 feet of floor space. In marine engineering III feet, and in metallurgy and the chemical departments each have 426 square feet of space. Prof. Thurston advises not less than 30 square feet per student in class rooms, in drawing rooms about 100 , and in laboratories from I 50 to 500 feet, according to character of the work to be done and magnitude of the space required for machinery and apparatus.

The Brunswick school has 4 ro feet floor space per student in all departments. At Karlsruhe $45^{\circ}$ square feet is provided in the department of electrotechnics. The cost of the Berlin building is placed at 1000 dollars per student, of the Brunswick buildings 2000 dollars per student. From these data it may be seen that an institution which may be called upon to provide for a thousand students at once, and perhaps three or four times that number in the near future, must be planned upon a most liberal scale to meet the demands which shall be made upon it.

As to the scope of the work of the new school, Prof. Johnson's proposed scheme is as follows :-

A. Colleges. Courses of four years with a high school preparation : (I) College of Science ; (2) College of Engineering ; (3) College of Commerce. All these to be of university grade, with degrees conferred at graduation. B. Schools. Courses of three years with a grammar school preparation: (I) Manual Train School ; (2) Domestic Science School ; (3) School of Industrial Design ; (4) School of Commerce. All these to be of high-school grade. Diplomas to be given at graduation. C. Artisan Day School. Courses of three years, with a preparation in reading, writing and arithmetic. To include courses of instruction in subjects of essential importance in the practice of the various trades. D. Night School for day workers. Preparation same as C. Regular courses, and also special instructions of practical value to day workers of all sorts and all employments.

Prof. Jolnson, Dr. Alderson and Dr. Gray studied a number of the industries of Pittsburg, and in all their reports they emphasised the value of the secondary schools. The question of monotechnic or trade schools, i.e. where a young man or woman can learn at least the rudiments of a trade by which they propose to make their living, was also discussed; and it is the opinion of both committee and advisory board that in due time this part of the problem should be given earnest consideration.

Dr. Alderson recommended that the six following departments should be established, each with several branches :(1) Engineering, (2) Secondary Education, (3) Library Economy, (4) Domestic Arts and Sciences, (5) Art, (6) Evening Instruction.

Dr. Gray recommends that the institute should offer a course of instruction covering the whole nine years of study ; that it be divided into two distinct schools, a secondary and upper secondary, and a higher college or professional school. $\mathrm{He}$ advises that the secondary school commence first above the grade schools with a minimum age limit of fourteen years, and that the course of this instruction should include all the subjects commonly given in the best high schools with the possible exception of Latin and Greek, and in addition the subjects more commonly given in business schools or colleges, along with this course of class-room instruction, provision should be made for practical instruction, either manual or otherwise, bearing upon the particular branch of industry which the scholar intends to enter.

Dr. Gray recommends a good sound course in English for students of the secondary school, but not a study of foreign languages. He also recommends that the technical college or professional school be open only to a selected small number of students who have shown special fitness for the work, and that the entrance requirements should be considerably higher than is usual in existing technical colleges. For this department extensive laboratory practice is recommended and thorough drill in the methods of testing properties of matter and in investigational work.

The general scheme laid out for the great technical university by Dr. Thurston comprises the following colleges:- (I) Mechanical Engineering and the Mechanic Arts, with eight different departments of Mechanical Engineering; (2) Civil Engineering, with six departments; (3) Architecture, with three departments; (4) Mines and Metallurgy, with two departments;

$$
\text { No. I666, vOL. 64] }
$$


(5) Agriculture, with six departments ; (6) Applied Chemistry, with four departments ; (7) Physics, with two departments ; (8) Fine Arts, with three departments ; (9) Business, with four departments ; (10) Navigation and Marine Transportation, with two departments ; (II) Mathematics, with two departments ; (I2) Politics and Ecomomics, with four departments ; (13) Languages and Literature, with four departments ; (14) Philosophical Science and Ethics; (I5) Biology; (16) The Preparatory College (standard curriculum).

In his presidental address to the section of social and economical science, Prof. C. M. Woodward referred to the report of the advisory committee on the Carnegie Technical School in the following terms:- "For a variety of excellent reasons the committee reaches the conclusion that some new kind of preparation for the work of life must be introduced into the school training of both boys and girls. It then proceeds to outline a technical college, a technical high school and an artisan day and evening school, which are to meet this demand.

"The artisan day and evening school is somewhat of the order of German and English low-grade technical schools. I earnestly hope that the suggestion of this school may be adopted that the experiment may be fairly tried in America. The plan for a technical college is in complete harmony with the best engineering schools.

"The scheme for a technical high school, however, seems to me faulty. This school would be of high-school grade, taking pupils from the grammar schools and covering presumably four years. The normal ages of entrance and graduation would accordingly be fourteen and eighteen. Three things in the committee's outline of this technical high school deserve attention : (I) The elective principle is to be recognised, the student selecting the required number of courses under the direction of the director of the school. Here the pupil at a tender age (only fourteen or fifteen) is asked to surrender his birthright to the privilege of choice when he is eighteen.

"(2) The course in mathematics - which begins with elementary algebra-is to include the elements of calculus ! Of course, it must include solid geometry, higher algebra, trigonometry and analytical geometry! One rarely meets with such an astounding proposition from engineers who are supposed to have studied mathematics and to know what they are talking about. They might as well propose that the pupils shall take thermodynamics in a short course of lectures. To be sure, similar ambitious schemes have been proposed elsewhere for boys just out of the grammar school, but they came from people who could have known very little mathematics, and nothing of the uses of the calculus. This criticism may seem trivial, but in more than one place the scheme attempts too much.

" (3) The technical studies suggested take the form of trade work or special employments, with well equipped shops and experimental laboratories under the direction of expert artisans.

"What Mr. Carnegie will do with this last suggestion remains to be seen, but any attempt to embody it in a real technical high school of secondary grade will be full of interest to the educational world. If any man was well prepared to give the scheme a fair trial, that man is Andrew Carnegie; but it will cost a vast amount of money and its experience will teach us how not to do many things.

"I have high respect for the members of the advisory com mittee, but $\mathbf{I}$ think a less ambitious scheme would be more successful. You cannot teach the higher mathematics in a high school, and I have no great faith in the value of attempts to teach employments, commercial or industrial, within the limits of any secondary school. Such attempts are certain to mislead and ultimately hinder those they aim to help. Any trade or special employment must be dwarfed and narrowed before it can be brought down to the grasp of an untrained boy, and its very narrowness unfits it for the best educational uses.

"The school is the place where one should learn the fundamental unchanging laws and manifestations of force and materials. Special occupations, like special constructions, should be analysed in their elements, and pupils should become expert in such analyses, in so far as they involve universal elements that pupils can comprehend. But there are many things essential to a business employment, which cannot even be apprehended in school."

From the foregoing it will be seen that much difference of opinion exists as to the nature and extent of the subjects which should be included in the curriculum of a large technical school. Three different and distinct forms of school, which may be combined as parts of one complete technical university, have been proposed. If the whole scheme is accepted by Mr. Carnegie, there will be, in the first place, a first-class technical college. "This college," says the committee, "should be made attractive to the greatest scholars in the fields of physical and chemical science. To obtain and hold such men they must be given ample opportunities for research. This college must be supplied, therefore, not only with great experimental shops and laboratories for students' use, but in all departments there should be splendidly equipped laboratories of investigation and research, under the direction of the head of such department, and with a full corps of assistants for the carrying on of all lines of investigation which are now partly or wholly unprovided for in America." There will also be a Technical High School to carry on work above that of the public grammar school, and day and evening classes for the benefit of those who are unable to take advantage of the more complete courses in this school. Mr. Carnegie has now to decide whether he will found a school for artisans, a technical high school or a technical college, or, if his ambition mounts so high, a true technical university including them all.

\section{UNIVERSITY AND EDUCATIONAL} INTELLIGENCE.

THE building fund of $\mathrm{I} 50,000 \mathrm{l}$, which it is proposed to raise for the Glasgow and West of Scotland Technical College, has reached about $100,000 /$., and Mr. Carnegie has promised to subscribe one-half the deficiency upon the condition that the other half is promptly obtained.

THE position of science and technical instruction in schools inspected by officers of the Secondary Branch of the Board of Education can be seen in vol. ii. of the Report just issued by the Board, containing extracts from the inspectors' reports for the year 1900. Improvement is manifest in the larger technical schools in the teaching of advanced science. General improvement is also reported in the mode of teaching experimental science. "Moreover," remarks Mr. A. E. Tutton, F.R.S., "the influence of the advocates of the heuristic method of teaching has proved to be so far effective that the general atten. tion of teachers has been directed to the educative value of calling forth the highest thinking and experimenting powers of their pupils." Dr. H. H. Hoffert also reports that "there is amongst the teachers a widely spread spirit of enthusiastic eagerness to ascertain the best methods of instruction and to apply them in their own schools." The movement for reform is being felt in the teaching of mathematics, and Mr. J. Brili contributes a short special report upon the subject to the volume just issued. The work being done in the Schools of Science is favourably reported upon by all the inspectors. In these schools five or six hours a week are given to experimental science, two or three to drawing and geometry, about five to mathematics, and eight or ten to literary subjects. Beyond this minimum requirement the extra time at the disposal of the school is given to languages, to science, to commercial subjects, or to manual occupations according to the particular type of the school. In fact, these schools possess a curriculum which is adapted to modern requirements, and in most of them excellent work is being done, not only in science and art, but also in literary subjects.

A FULL report of the opening of the Harper-Adams Agricultural College at Edgmond, Newport, by Mr. Hanbury, the President of the Board of Agriculture, appears in the Nezoport and Market Drayton Advertiser of September 28. The College owes its establishment to the late Mr. Thomas HarperAdams, who left a large sum of money and an estate in order to found it, It is provided with lecture rooms and laboratories in which work can be carried on in physics, chemistry, biology, and other sciences connected with agriculture. The farm attached to the College is about 180 acres in extent and is intended for experimental purposes; and all the work will be arranged with the object of instructing students in the practical management of a farm on modern business lines. The Salop County Council make a grant of $1000 \%$. a year towards the College funds, and together with the Stafford County Council offer a certain number of scholarships tenable at the College. The Principal is Mr. P. Hedworth Foulkes. In opening the College, Mr. Hanbury referred to the small sum available for agricultural education. At present the Board of Agriculture had to spend, in grants, the small sum of $8000 l$. for the whole of the United Kingdom. In France, for the same purpose, 153,00ol.

NO. I666, VOL. 64] 